

6 OPEN ACCESS

Received: 03.12.2021

Accepted: 07.12.2021

Published: 26.12 .2021

Citation: Prakash E, Chidambaram IA, Paramasivam B (2021) Cascade 2DOF-PIDN-FOPIDN Controller based AGC System of a Multi-Source Restructured Power System with HES and IPFC. Indian Journal of Science and Technology 14(47): 3442-3455. https://doi.org/ 10.17485/IJST/v14i47.2166

* Corresponding author.

drelamprakash@gmail.com

Funding: None

Competing Interests: None

Copyright: ( 2021 Prakash et al. This is an open access article distributed under the terms of the Creative Commons Attribution License, which permits unrestricted use, distribution, and reproduction in any medium, provided the original author and source are credited.

Published By Indian Society for Education and Environment (iSee)

ISSN

Print: 0974-6846

Electronic: 0974-5645

\section{Cascade 2DOF-PIDN-FOPIDN Controller based AGC System of a Multi-Source Restructured Power System with HES and IPFC}

\author{
E Prakash $^{1 *}$, I A Chidambaram², B Paramasivam ${ }^{3}$ \\ 1 Research Scholar, Department of Electrical Engineering, Annamalai University, \\ Annamalainagar, Tamilnadu, India \\ 2 Professor, Department of Electrical Engineering, Annamalai University, Annamalainagar, \\ Tamilnadu, India \\ 3 Associate Professor, Department of Electrical and Electronics Engineering, Government \\ College of Engineering, Bodinayakkanur, Theni, Tamilnadu, India
}

\section{Abstract}

Background/Objectives: The essential goal of the Automatic Generation Control (AGC) framework is to limit the transient deviations in the area frequencies and tie-line power oscillations and to guarantee their steady-state errors to be zeros. Methods: The article proposes a new cascade Two Degree of Freedom PID including filter along with Fractional Order PID together with filter (2DOF-PIDN-FOPIDN) regulator which are designed using Buzzard Optimization Algorithm (BUZOA) technique and executed in the secondary controller of the AGC loop of a two-region thermal-hydro-wind restructured power system. The proposed novel 2DOF-PIDN-FOPIDN regulator consists of an integer order cascaded controller through a fractional order controller. It guarantees with the aim of the controller intend process be easy to execute and has an outstanding ability to manage parameters improbability, removes steady-state errors, and guarantees enhanced stability as compared with the 2 DOF-FOPIDN regulators. The controller gains and other control constraints were tuned with novel and efficient meta-heuristic optimization techniques such as the BUZOA technique. Further, the AGC loop of the proposed system is enhanced with the application of sophisticated Hydrogen Energy Storage (HES) units connected in the control area and FACTS devises like Interline Power Flow Controller (IPFC) which is also introduced in series with tie-line of the interconnected areas of the restructured power system under different possible exchanges. Findings and Novelty: The reproduction results uncover that the predominance of a new cascade 2DOFPIDN-FOPIDN regulator, the unique presentation of AGC system of a two-region interconnected restructured power framework has worked on as far as less peak variation and settling time of region frequencies and tie-line power in different transactions as contrasted 2 DOF-FOPIDN regulators. Moreover, the execution of HES and IPFC units effectively arrest the fundamental decrease in frequency like the tie-line power deviation after an abrupt load disturbance to 
give the critical advantage of stability.

Keywords: Buzzard Optimization Algorithm; 2-DOF-FOPIDN controller; Cascade 2DOF-PIDN-FOPIDN controller; HES; IPFC

\section{Introduction}

The effective activity of interconnected power systems involves the coordinating of allout generation through absolute demand in load and the related losses in the system. The examination and plan of the AGC system of individual generators ultimately controlling enormous interconnections between various control regions assume an indispensable part in the computerization of power systems. The essential targets using AGC is to manage frequency to the predetermined ostensible worth and to keep up with the trade power among the control regions at the programmed values by varying the output of the chosen generators $^{(1)}$. AGC activity is synchronized by the Area Control Error (ACE) with the assistance of framework frequency and tie-line streams. In each zone, AGC screens the locale frequency and tie-line power stream and works out the net change in the power generation obliged subject to the variation in demand. The set mark of the generators contained by the region is altered to keep up with the ACE at a little worth. An ACE signal is portrayed as a straight mixture of change in the tie-line power exchange and variations in frequency. The deliberate ACE signal while overseeing the output of the AGC circle, since the ACE signal is hurried toward zero through the AGC, frequency and tie-line power errors will be constrained to zeros ${ }^{(2)}$.

The newly rebuilt power structure comprises Genco, Disco, Transco, and ISO. The AGC in a restructured power trade must be intended to reflect on diverse varieties of feasible transactions, for instance, Poolco, bilateral transactions, and a mixture of these two ${ }^{(3)}$. In the context of the bilateral contact, Disco has the freedom to acquire power from some accessible Gencos in their individual area or supplementary regions. So, the standard AGC two-zone interconnected power system is controlled as per the impact of bilateral agreements on the dynamics ${ }^{(4)}$. The ostensible working mark of power system modify since its pre-decided worth exposed to any unsettling influence because of the deviation made by the working point in the apparent frequency in system and programmed tie-line power exchange to various regions, which is tragic. Accordingly, an AGC conspires principally coordinates a reasonable control system for an interconnected power system to bring the frequencies of every area and the tieline power back to an exceptional set point worth effectively after the load change. Vigorous optional controllers are fundamental to holding a flat frequency profile. A few progressed controller designs and policies have been suggested in the literature for $\operatorname{AGC}^{(4,5)}$.

The fundamental points of the PID regulator, a derivative mode, perk up the constancy of the system In any case, as the input signal has a quick corner, the derivative expression resolve conveys nonsensical dimension manage inputs to the system. Moreover, any clamor within the input signal will achieve tremendous system input signals that guide to disarray in realistic applications. The reasonable answer for this issue is driving the first-order filter on the derivative expression and tuning its pole so the chatting because of the noise doesn't happen in view of the fact that it attenuates high-frequency clamor ${ }^{(6)}$. A PID with a derivative Filter (PIDN) regulator had been considered in that assessment. The exhibition of PIDN regulators can be perked up by means of partial investigation. Further could enhance the system performance, fractional-order PID regulators have been considered and it gives adaptability in controlling purposes which assists with arranging the AGC issues and excellent competence of managing parameter ambiguity, removal of steady-state error, and ensures enhanced constancy ${ }^{(7)}$. 
Of late, two degrees of freedom (2-DOF) stand controller structures have acquired a lot of thought in the control society. The flexibility of 2-DOF is more prominent than a (1-DOF) is as per the viewpoint of achieving raised show in setpoint pathway and the rule in the event of interference inputs ${ }^{(8,9)}$. The commonness and advantage of fractional order regulators, close by two-level of opportunity, are yet to be examined in the field of AGC. An integer order regulator fell with a fractional-order regulator and guaranteed that the regulator plan strategy is easy to carry out. In this examination, a new cascade 2 DOF-PID including filter along with Fractional Order PID together with filter (2DOF-PIDN-FOPIDN) controller are planned and carried out in the optional regulator of AGC loop of the test system. The huge benefit of cascade 2DOF-PIDN-FOPIDN controllers is exceptionally appropriate for controlling purposes which assists with planning the AGC issues and incredible ability to take care of parameter vulnerability, eliminating steady-state errors, and ensuring better stability. The regulating limits for cascade 2DOF-PIDN-FOPIDN are fine-tuned employing Buzzard Optimization Algorithm (BUZOA) and its exhibition is contrasted and the 2-DOF-FOPIDN controller. BUZOA technique is one of the advanced heuristic calculations and has an extraordinary potential to tackle complex optimization problems ${ }^{(10)}$.

To make up for the sudden load changes, a balancing power generation and load demand is forever a difficult course of action, mostly at peak load demand. Accordingly, there might be severe alarms about the consistent function of the power system. In this way, it is important to incorporate rapid-stand-in Energy Storage schemes that contain an ability limit alongside the kinetic energy of the generator rotors is prudent to soggy out the large frequency variations ${ }^{(11)}$. Notwithstanding, because of economic conditions, it's anything but conceivable to put an ESS in every one of the areas. The coordinated control activities between ESS and FACTS devices in the AGC system have been found to manage the system states in a quick and efficient way ${ }^{(12)}$. In this examination, the improvement of the AGC system a refined utilization of HES units associated with the control area of the proposed power system. A FACTS device like IPFC is additionally presented in series with tie-line interconnected regions.

\section{Modeling of Two-Area Restructured Power System}

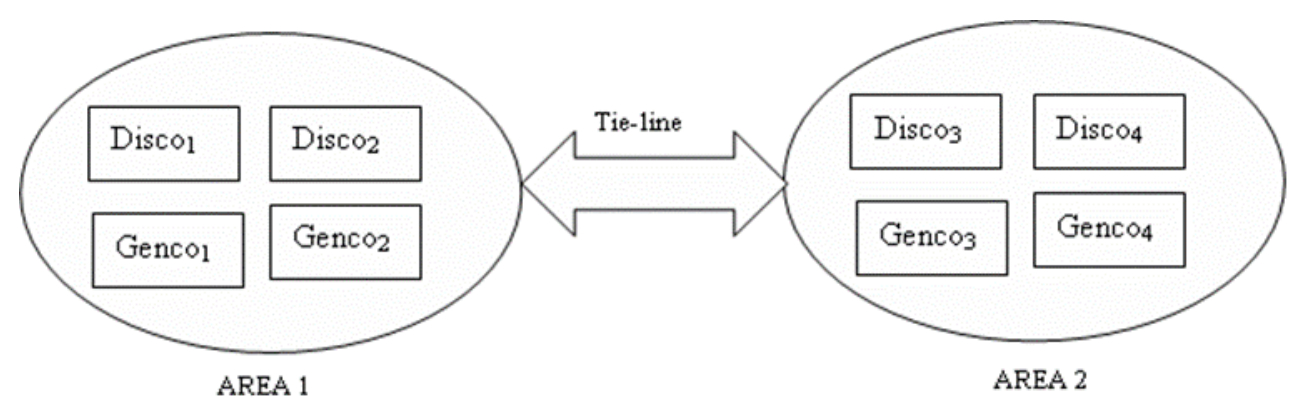

Fig 1. Schematic representation two-area restructured power system

The schematic illustration of a two-region interconnected restructured power system has displayed in Figure 1. The rebuilt power framework structure changed with the objective that it would permit the production of honestly unequivocal endeavors for Genco, Transco and Disco. A Disco in every space can contract with Gencos in its own or different regions. The contrasting $\mathrm{DPM}$ is given as follow

$$
D P M=\left[\begin{array}{llll}
c p f_{11} & c p f_{12} & c p f_{13} & c p f_{14} \\
c p f_{21} & c p f_{22} & c p f_{23} & c p f_{24} \\
c p f_{31} & c p f_{32} & c p f_{33} & c p f_{34} \\
c p f_{41} & c p f_{42} & c p f_{43} & c p f_{44}
\end{array}\right]
$$

Where cpf speaks to contract participation factor \&bears a resemblance to signals might convey data regarding which the Genco needs to pursue the demanded load in Disco. The planed consistent state power flow on the tie-line is

$$
\triangle P_{\text {Tie } 12}^{\text {scheduled }}=\Sigma^{2}{ }_{i=1} \Sigma^{4}{ }_{j=3} c p f_{i j} \triangle P_{L j}-\sum_{i=3}^{4} \sum_{j=1}^{2} c p f_{i j} \triangle P_{L j}
$$

The tie-line (actual) power as

$$
\triangle P_{\text {Tie } 12}^{\text {actual }}=\frac{2 \pi T_{12}}{s}\left(\triangle F_{1}-\triangle F_{2}\right)
$$


At some intervention, the representation of tie-line error and error signal be as

$$
\begin{aligned}
& \Delta P_{\text {Tie 12 }}^{\text {Error }}=\Delta P_{\text {Tie 12 }}^{\text {actual }}-\Delta P_{\text {Tie } 12}^{\text {scheduled }} \\
& A C E_{1}=\beta_{1} \triangle F_{1}+\triangle P_{\text {Tie } 1,2 \text { error }} \\
& A C E_{2}=\beta_{2} \triangle F_{1}+\triangle P_{\text {Tie } 2,1 \text { error }}
\end{aligned}
$$

The GENCO generation for $\mathrm{i}^{\text {th }}$ Genco to DPM passages be as

$$
\triangle P_{G i}=\sum_{j=1}^{4} c p f_{i j} \triangle P_{L j}
$$

\section{Design of Proposed Controllers Using Buzzard Optimization Algorithm}

\subsection{Control structure of 2DOF-FOPIDN}

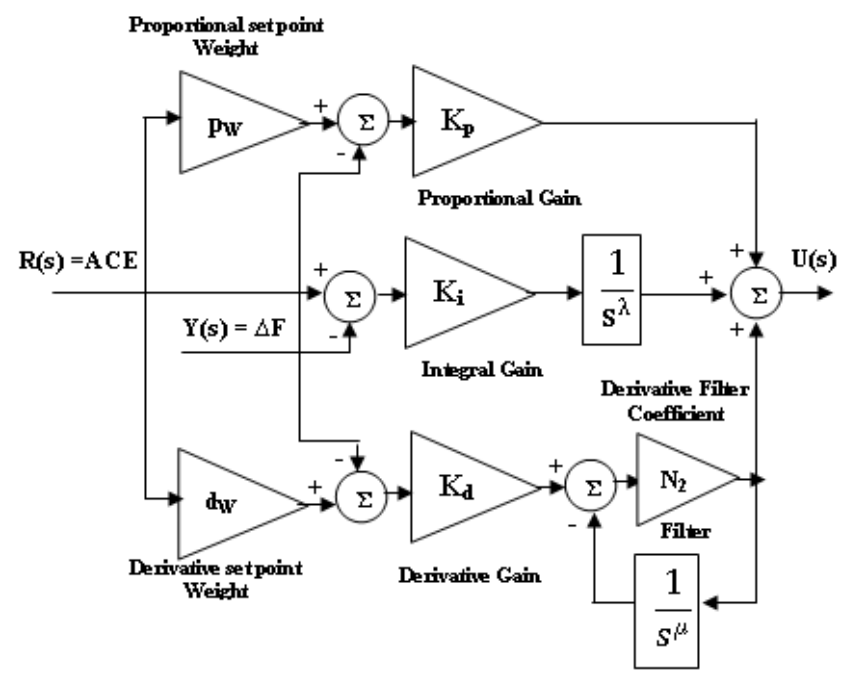

Fig 2. Scheme representations of 2DOF-FOPIDN controllers

The construction of a 2DOF-FOPIDN regulator is displayed in Figure 2. It includes setpoint weights $\left(\mathrm{p}_{W}\right.$ and $\left.\mathrm{d}_{W}\right)$, regulators gains (Kp, Ki, and Kd), derivative filter coefficient (N2) and fragmentary vital and derivative orders $(\lambda$ and $\mu$ ). In this Figure 2, $\mathrm{C}(\mathrm{s})$ is a $1 \mathrm{DOF}$ regulator, $\mathrm{D}(\mathrm{s})$ is the load unsettling influence, and $\mathrm{F}(\mathrm{s})$ goes about as a pre-filter on the reference signal. For a parallel 2DOF-FOPIDN, $\mathrm{C}(\mathrm{s})$ and $\mathrm{F}(\mathrm{s})$ are given by:

$$
\begin{gathered}
C_{s}(s)=K_{p}+\frac{K_{i}}{s^{\lambda}}+K_{d} s^{\mu}\left(\frac{N_{2}}{N_{2}+s^{\mu}}\right) \\
F_{S}(s)=p_{W} K_{p}+\frac{K_{i}}{s^{\lambda}}+d_{W} K_{d} s^{\mu}\left(\frac{N_{2}}{N_{2}+s^{\mu}}\right)
\end{gathered}
$$

The controller error inputs are the individual ACE signals and ISE are given by Eqn. (5); (6) and (10).

$$
J_{i}=\int_{o}^{t_{s i m}}\left[\left(A C E_{i}\right)^{2}\right]
$$


The BUZOA enhancement procedure is utilized to choose the ideal boundaries of 2DOF-FOPIDN regulators with the objective to restrict Integral Square of ACE signals are expressed in Eqn (10). The plan issue can be formed as the accompanying streamlining issue.

Minimize $_{i}$

Subject to

$$
\begin{aligned}
& K_{p}^{\text {min }} \leq K_{p} \leq K_{p}^{\text {max }}, K_{i}^{\text {min }} \leq K_{i} \leq K_{i}^{\text {max }}, K_{d}^{\text {min }} \leq K_{d} \leq K_{d}^{\text {max }}, N_{2}^{\text {min }} \leq N_{2} \leq N_{2}^{\text {max }}, \lambda^{\text {min }} \leq \lambda \leq \lambda^{\text {max }}, \mu^{\text {min }} \leq \mu \leq \mu^{\text {max }}, \\
& p_{W}^{\text {min }} \leq p_{W} \leq p_{W}^{\text {max }}, d_{W}^{\text {min }} \leq d_{W} \leq d_{W}^{\text {max }}
\end{aligned}
$$

\subsection{Control structure of cascade 2 DOF-PIDN-FOPIDN controller}

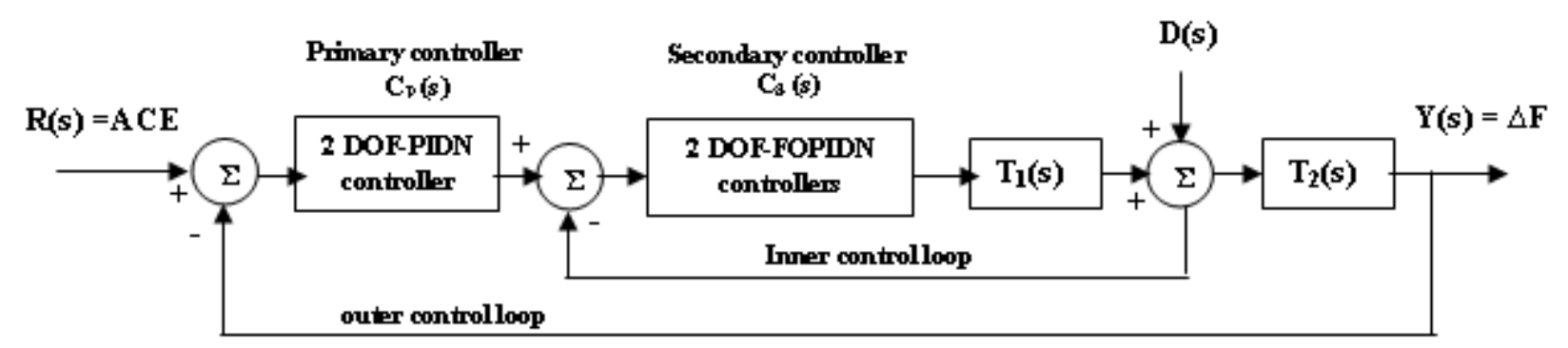

Fig 3. Schematic diagram of cascade controller

The schematic diagram of the cascade regulator shows up in Figure 3. The cascade regulator gives an extra sensor to weaken the interference before affecting the output quantity. In this regulator, the control signal is dealt with in two stages: the inward circle control signal and the external circle control signal. The inward circle control signal is faster by which the framework dynamics are accelerated to deliver a speedier response. The control indication of the course controller is given in Eqn. (13).

$Y(s)=\left(\frac{T_{1}(s) * T_{2}(s) * C_{p}(s) * C_{s}(s)}{1+T_{2}(s) * C_{s}(s)+T_{1}(s) * T_{2}(s) * C_{p}(s) * C_{s}(s)}\right) R(s)+\left(\frac{T_{1}(s)}{1+T_{2}(s) * C_{s}(s)+T_{1}(s) * T_{2}(s) * C_{p}(s) * C_{s}(s)}\right) D(s)$

Where $\mathrm{T}_{1}(\mathrm{~s})$ and $\mathrm{T}_{2}(\mathrm{~s})$ are transfer functions, and $\mathrm{C}_{p}(\mathrm{~s})$ and $\mathrm{C}_{s}(\mathrm{~s})$ are the transfer functions of primary and secondary controllers, respectively. Furthermore, $\mathrm{D}(\mathrm{s})$ is the disturbance signal, and $\mathrm{R}(\mathrm{s})$ is the ACE signal. To affix an enhanced execution in this examination, the cascade controller is configured by an integer and fractional order operator incorporating two degrees of freedom technique to produce a 2-DOF-PIDN-FOPIDN regulator. The degree of freedom control scheme gives an output which is the distinction between a position signal and a calculated output of the system. It processes a biased contrast signal for every proportional, integral, and derivative action due to particular set-point weights. The cascade aggregate of 2 DOFPIDN-FOPIDN is suggested as an optional controller through restructured AGC system. The comprehensive arrangement of the proposed 2 DOF-PIDN-FOPIDN regulators is depicted in Figure 4.

The schematic diagram of the cascade regulator shows up in Figure 3. The cascade regulator gives an extra sensor to weaken the interference prior to affecting the output quantity. In this regulator, the control signal is dealt with in two stages: the inward circle control signal and the external circle control signal. The inward circle control signal is faster by which the framework dynamics are accelerated to deliver a speedier response. The control indication of the course controller is given in Eqn. (13).

In Figure 4 shows that in the inner loop, the 2-DOF-FOPIDN controllers are helped by a derivative filter $\left(\mathrm{N}_{2}\right)$ to alleviate the noise produced by any sensors through the feedback path. What is more, the 2 DOF-PIDN controllers with derivative filter $\left(\mathrm{N}_{1}\right)$ are available in the outer loop. The proposed 2 DOF-PIDN and 2 DOF-FOPID are the master and slave controllers whose transfer functions $\mathrm{C}_{p}(\mathrm{~s})$ and $\mathrm{C}_{s}(\mathrm{~s})$ are given by Eqns. (14) and (15), separately. The $\mathrm{F}_{p}(\mathrm{~s})$ and Fs(s) are pre-channels on $\mathrm{C}_{p}(\mathrm{~s})$ and $\mathrm{C}_{s}(\mathrm{~s})$ given by Eqns. (16) and (17) individually.

$$
\begin{gathered}
C_{P}(s)=\frac{\left(K_{P}+K_{D} N_{1}\right) s^{2}+\left(K_{P} N_{1}+K_{I}\right) s+K_{I} N_{1}}{s\left(s+N_{1}\right)} \\
C_{s}(s)=K_{p}+\frac{K_{i}}{s^{\lambda}}+K_{d} s^{\mu}\left(\frac{N_{2}}{N_{2}+s^{\mu}}\right)
\end{gathered}
$$




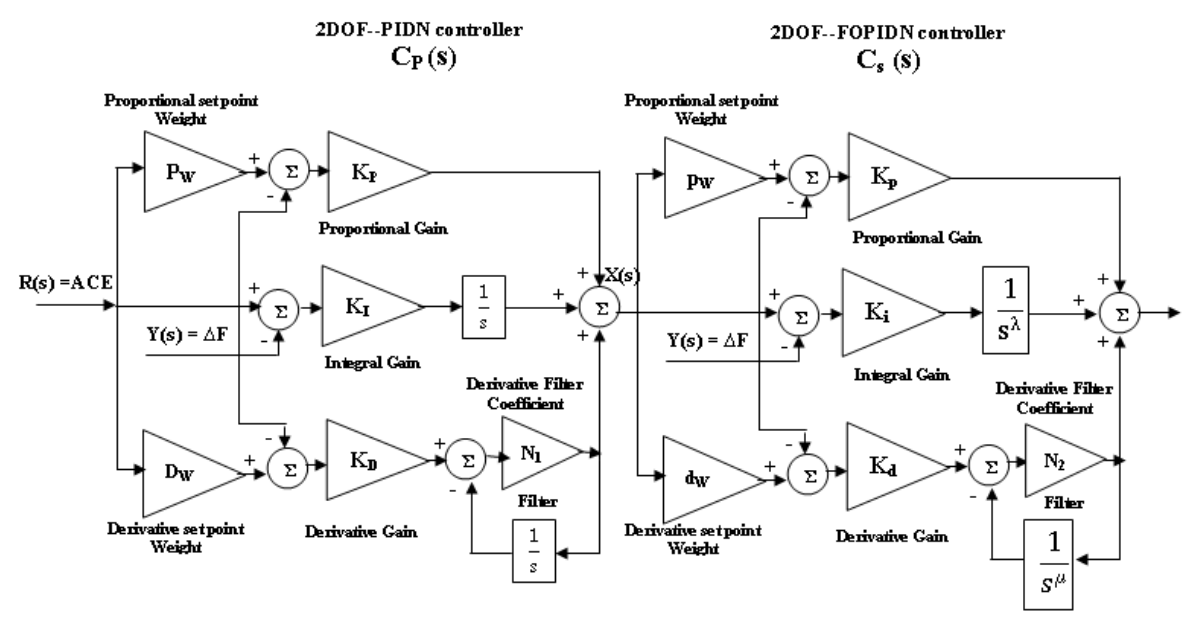

Fig 4. Block diagram for 2DOF-PIDN-FOPIDN controller

$$
\begin{gathered}
F_{P}(s)=\frac{\left(P_{W} K_{P}+D_{W} K_{D}\right) s^{2}+\left(P_{W} K_{P} N_{1}+K_{I}\right) s+K_{I} N_{1}}{\left(K_{P}+K_{D} N_{1}\right) s^{2}+\left(K_{P} N_{1}+K_{I}\right) s+K_{I} N_{1}} \\
F_{S}(s)=p_{W} K_{p}+\frac{K_{i}}{s^{\lambda}}+d_{W} K_{d} s^{\mu}\left(\frac{N_{2}}{N_{2}+s^{\mu}}\right)
\end{gathered}
$$

The control signal of the 2-DOF-PIDN-FOPIDN controller is determined by the transfer function, $\mathrm{C}_{p}(\mathrm{~s})$, and $\mathrm{C}_{s}(\mathrm{~s})$ of 2 DOFPIDN and 2 DOF-FOPID controllers, and the control signal U(s) after two phases is assessed by Eqn. (18). Where R(s) is the area control error signal (ACE) and $\mathrm{Y}(\mathrm{s})$ is the output signal of $\Delta \mathrm{F}$.

$U(s)=\left[\begin{array}{c}\left(\frac{\left(P_{W} K_{P}+D_{W} K_{D}\right) s^{2}+\left(P_{W} K_{P} N_{1}+K_{I}\right) s+K_{I} N_{1}}{\left(K_{P}+K_{D} N_{1}\right) s^{2}+\left(K_{P} N_{1}+K_{I}\right) s+K_{I} N_{1}}\right) \\ *\left(p_{W} K_{p}+\frac{K_{i}}{s^{\lambda}}+d_{W} K_{d} s^{\mu}\left(\frac{N_{2}}{N_{2}+s^{\mu}}\right)\right)\end{array}\right] R(s)-\left[\begin{array}{c}\left(\frac{\left(K_{P}+K_{D} N_{1}\right) s^{2}+\left(K_{P} N_{1}+K_{I}\right) s+K_{I} N_{1}}{s\left(s+N_{1}\right)}\right) \\ *\left(K_{p}+\frac{K_{i}}{s^{\lambda}}+K_{d} s^{\mu}\left(\frac{N_{2}}{N_{2}+s^{\mu}}\right)\right)\end{array}\right] Y(s)$

The BUZOA technique is utilized to decide the ideal requirements of 2-DOF-PIDN-FOPIDN controllers with the target to limit the Integral Square of ACE is expressed as

$$
J_{i}=\int_{o}^{t_{s i m}}\left[\left(A C E_{i}\right)^{2}\right] d t
$$

The problem formation is the coined through controller parameter bounds. Therefore, the design problem can be written by

\section{Minimize $J$}

Subject to

$$
\begin{aligned}
& K_{P}^{\min } \leq K_{P} \leq K_{P}^{\max }, K_{I}^{\min } \leq K_{I} \leq K_{I}^{\max }, K_{D}^{\min } \leq K_{D} \leq K_{D}^{\max }, N_{1}^{\min } \leq N_{1} \leq N_{1}^{\max }, P_{W}^{\min } \leq P_{W} \leq P_{W}^{\max }, D_{W}^{\min } \leq \\
& D_{W} \leq D_{W}^{\max }, K_{p}^{\min } \leq K_{p} \leq K_{p}^{\max }, K_{i}^{\min } \leq K_{i} \leq K_{i}^{\max }, K_{d}^{\min } \leq K_{d} \leq K_{d}^{\max }, N_{2}^{\min } \leq N_{2} \leq N_{2}^{\max }, \lambda^{\min } \leq \lambda^{\max }, \\
& \mu^{\min } \leq \mu \leq \mu^{\text {max }}, p_{W}^{\text {min }} \leq p_{W} \leq p_{W}^{\max }, d_{W}^{\min } \leq d_{W} \leq d_{W}^{\max }
\end{aligned}
$$

The ACE minimization for optimal estimations of 2-DOF-PIDN-FOPIDN controller coefficients has been solved utilizing the BUZOA technique. The presentation of the suggested regulator has likewise been contrasted with the existing 2-DOF- FOPIDN controller. 


\subsection{Design of proposed controller using Buzzard Optimization Algorithm}

Buzzard Optimization Algorithm (BUZOA) technique is coined by summarized through simulation with the activities of collective flight (group) buzzards (vultures) ${ }^{(10)}$. Let us assume d -dimensional buzzard search space. i-th particle is described by the vector of position $\mathrm{L}_{i}$ as follows in this $\mathrm{d}$-dimensional space:

$$
L_{i}=\left(l_{i 1}, l_{i 2}, l_{i 3}, \ldots . . l_{i d}\right)
$$

$\mathrm{C}$-vector is the ability of smell, and the ability of taste for the $\mathrm{i}$-th particle is defined by the vector $\mathrm{C}_{i}$ as follows:

$$
C_{i}=\left(c_{i 1}, c_{i 2}, c_{i 3}, \ldots \ldots c_{i d}\right)
$$

The best position which $\mathrm{i}$-th particle is found is the vector $C_{i, \text { best }}^{*}$ and are shown as follows:

$$
C_{i, b e s t}^{*}=\left(c_{i 1}^{*}, c_{i 2}^{*}, c_{i 3}^{*}, \ldots \ldots c_{i d}^{*},\right)
$$

The best position that has found the best particle in the whole particle is $C_{g, \text { best }}^{*}$ and defines as follows:

$$
C_{g, \text { best }}^{*}=\left(c_{g 1}^{*}, c_{g 2}^{*}, c_{g 3}^{*}, \ldots \ldots c_{g d}^{*},\right)
$$

Whole particle best position: $C_{g, \text { best }}^{*}$, Each particle best position: $C_{i, \text { best }}^{*}$ and best position when compared to all particles: $C_{g, \text { best }}^{*}$,

Selection of position for best achieved at iteration no.1 $(=1)^{(10)}$.

$$
\begin{gathered}
C_{i, \text { best }}^{*}=L_{i}(t), \quad i=1,2,3, \ldots d \\
\operatorname{cost}\left(C_{i, \text { best }}^{*}\right)=\operatorname{cost}\left(L_{j}(t)\right)
\end{gathered}
$$

The location change and each particle cost for iteration algorithm as

$$
\left\{\begin{array}{c}
\text { if cost }\left(\left(L_{i}(t)\right)<\operatorname{cost}\left(C_{i, \text { best }}^{*}\right) \Rightarrow\right. \\
\text { elseNotchange } \\
\operatorname{cost}\left(C_{i, \text { best }}^{*}\right)=\operatorname{cost}\left(L_{j}(t)\right) i=1,2,3 \ldots d \\
C_{i, \text { best }}^{*}=L_{i}(t)
\end{array}\right.
$$

Each particle location update be as of,

$$
\begin{gathered}
L_{1}(t)=\alpha_{1} L(t-1)+\alpha_{2} * \operatorname{rand} *\left(C_{g, \text { best }}^{*}-C_{i}(t-1)\right) \\
L_{2}(t)=L_{1}(t)+\beta * \operatorname{rand}_{1} *\left(C_{s}(t)-C_{i}(t-1)\right)+(1-\beta) * \operatorname{rand}_{2} *\left(C_{v}(t)-C_{i}(t-1)\right)+\gamma * \operatorname{rand}_{1} \\
*\left(C_{g, \text { best }}^{*}-C_{i}(t-1)\right)+(1-\gamma) * \operatorname{rand}_{2} *\left(C_{g, \text { best }}^{*}-C_{i}(t-1)\right) L_{i}(t)=L_{i}(t-1)+C_{i}(t)
\end{gathered}
$$

$\alpha_{1}$ : inertia weighting factor; $\alpha_{2}, \beta$ and $\gamma$ : the training constant coefficient. rand $_{1}$, rand $2: 2$-random numbers bear uniform distribution in interval $0-1$. The function may change as equation ${ }^{(10)}$.

$$
\begin{gathered}
C_{1}(t)=\alpha_{1} C(t-1)+\alpha_{2} * \operatorname{rand} *\left(C_{i, \text { best }}^{*}-l_{i}(t-1)\right) \\
C_{2}(t)=C_{1}(t)+\beta * \operatorname{rand} *\left(C_{s}(t)-C_{i}(t-1)\right)+(1-\beta) * \operatorname{rand} *\left(C_{v}(t)-C_{i}(t-1)\right)+\gamma * \text { rand } *\left(C_{g, \text { best }}^{*}-l_{i}(t-1)\right) \\
C_{i}(t)=C_{i}(t-1)+L_{i}(t)
\end{gathered}
$$

$C_{i}(t-1)$, is the ability vectors in repetition $(t-1)^{\text {th }}$ and $L_{i}(t-1)$ is the Position vector in repetition $(t-1)^{\text {th }}$. To avert the undue raise in the ability and speed of a particle in the movement from one location to another location, the variation of the ability to the range is limited $\mathrm{C}_{\min } \leq \mathrm{C} \leq \mathrm{C}_{\max } . C_{s}$ - smell capability, is the vision capability and smell $=1$-taste. 


\section{Control design for HES and IPFC Units in AGC Loop}

According to the genuine perspective, it is seen that the IPFC unit facilitated in the tie-line among two locales is practical to settle the between region swaying mode, and sometime later, the HES unit is associated in the control region for giving the energy into the power framework should be proper control of the idleness form. The HES is displayed as a functioning force source to area 1 with the gain constant $\mathrm{K}_{H E S}$ and time constant $\mathrm{T}_{H E S}$. The IPFC unit is displayed as a tie-line power stream controller with a time constant $\mathrm{T}_{I P F C}$. The Linearized decrease model test framework with HES and IPFC units for the control arrangement has represented in Figure 5. The Structure of the IPFC-based damping controller is shown in Fig 6. The control gain of the HES unit, control parameters of IPFC is displayed in the appendix.



Fig 5. Reduction model for a two-area power system with HES and IPFC



Fig 6. Structure of IPFC-based damping controller

\section{Modeling of a Two-Area Restructured Power System with HES and IPFC}

The itemized move work block outline model of a course 2-DOF-PIDN-FOPIDN regulator dependent on a two-region multisource two-region multi-source thermal-hydro-wind rebuilt power framework with HES and IPFC units is shown in Figure 7. This test framework comprises of two Gencos and two Discos in the two regions. Gencos in region 1 comprises of thermal and hydro power units, and Gencos in region 2 has thermal and wind power units. A HES unit is associated with region 1, and an IPFC unit is associated in series with a tie-line. A course 2-DOF-PIDN-FOPIDN regulator has been utilized $s$ an auxiliary regulator of the AGC arrangement of every space. In this examination, the auxiliary regulators like 2-DOF-FOPIDN and course 2-DOF-PIDN-FOPIDN regulators are viewed as each in turn. The BUZOA method is utilized to choose the ideal boundaries of proposed regulators with the objective to restrict the ACE signal for the test framework. 


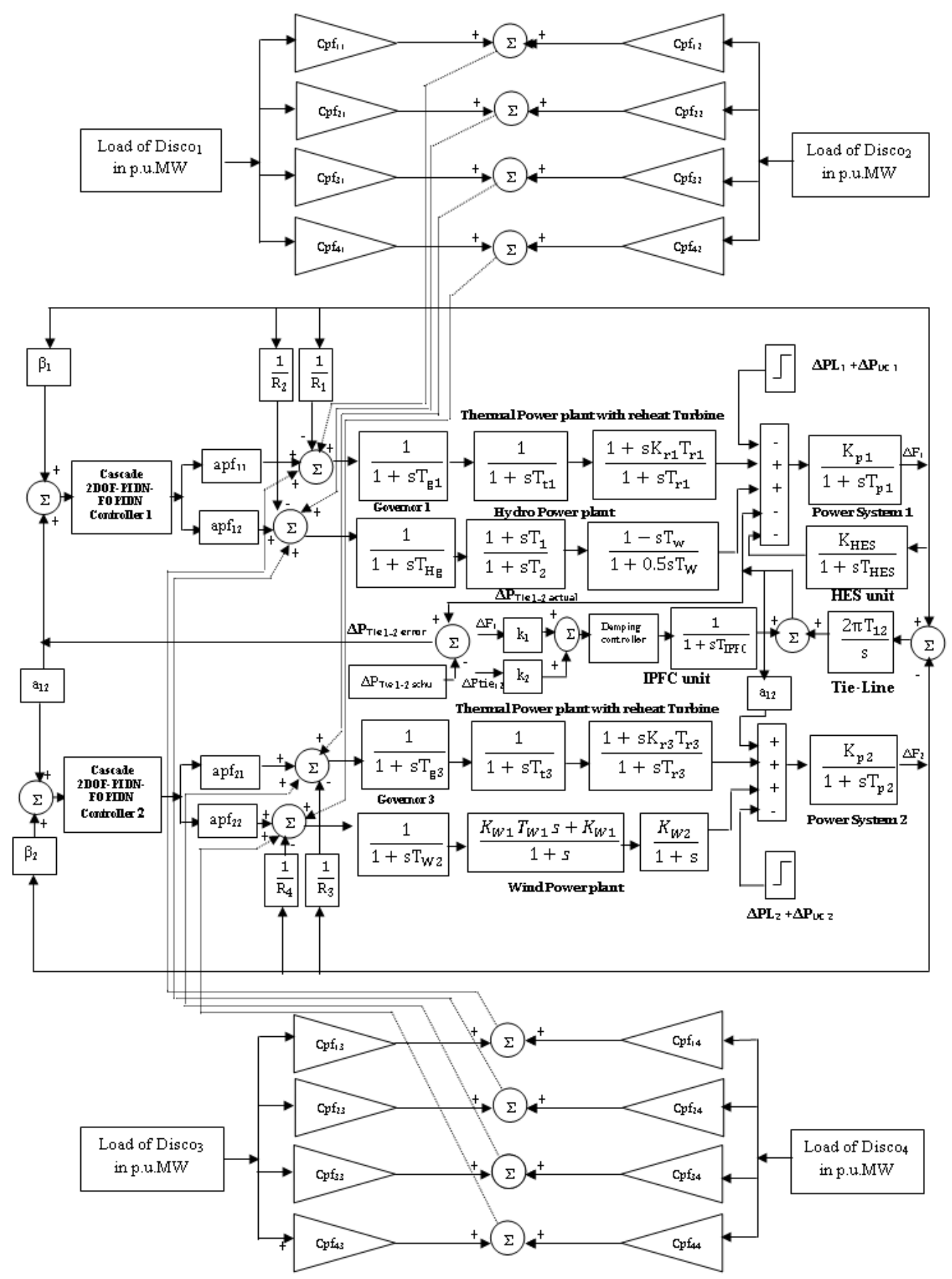

Fig 7. Linearized model of two-area multi-sourceinterconnected restructured power system with HES and IPFC units 


\section{Simulated Outcomes and Discussions}

In this examination, BUZOA optimization methods tuned 2DOF-FOPIDN and cascade 2-DOF-PIDN-FOPIDN regulators are planned and executed in a two-region multi-source thermal-hydro-wind restructured power system without/with HES and IPFC devices for the distinctive kind of exchange is thought of. The representation of the power system being scrutinized has been created in the Matlab/Simulink environment. The parameter values of the two-region multi-source AGC framework, HES, and IPFC boundaries are given in the appendix. A HES unit is presented in region 1, and an IPFC unit is related in series with a tie line nearer to region 1 . The BUZOA technique is for deciding the optimal parameters of 2DOF2DOF-FOPIDN and cascade 2-DOF-PIDN-FOPIDN regulators to limit the ACE signal for the binal-area multi-source thermal-hydro-wind restructured power with and without HES and IPFC units. At last, the optimal solution of control inputs is taken for enhancement issue to reach the aim of Eqn (10) is inferred utilizing the frequency abnormalities of areas and tie-line power changes.

\section{Scenario 1: Poolco based transactions}

For this situation of Poolco exchange, Gencos of every area oblige with Disco of that area. Accordingly, the Disco of region 1 is demanding load, though the Disco of region 2 isn't requesting any load. In the test framework, a load demand change of 0.25 , p.u.MW in each Disco in region 1 has been thought of. The DPM considered for the Poolco exchange is given by Eqn. (34). Disco 1 and Disco 2 demand imprecisely commencing their neighborhood Gencos, viz., Gencol and Genco2. Thus, it is considered here that the area participation factor (apf) is the entire equivalent worth 0.5 .

$$
D P M_{1}=\left[\begin{array}{llll}
0.5 & 0.5 & 0.0 & 0.0 \\
0.5 & 0.5 & 0.0 & 0.0 \\
0.0 & 0.0 & 0.0 & 0.0 \\
0.0 & 0.0 & 0.0 & 0.0
\end{array}\right]
$$

The optional regulators like 2DOF-FOPIDN and cascade 2-DOF-PIDN-FOPIDN regulators are viewed as each in turn. The BUZOA optimization strategies are utilized to choose the optimal parameters of 2DOF-FOPIDN and cascade 2-DOF-PIDNFOPIDN regulators' to restrict the ACE signal for the test system without/with HES and IPFC. These controllers are executed in a proposed test system under different un-contracted step load demand change conditions and compared with the 2DOFFOPIDN controller. The comparative transient performances of test systems with various sorts of controllers have shown up in Figure 8. The setting time and peak over/undershoot of area frequencies and tie-line power variations of a test system using BUZOA tuned 2DOF-FOPIDN and cascade 2-DOF-PIDN-FOPIDN controllers under different un-contracted step load demand changes are shown in Table 1 and Table 2 respectively. From Table 1 and Table 2and Figure 8, it tends to be seen that the proposed 2-DOF-PIDN-FOPIDN regulator has better unique responses of frequency variations of every area and tieline power variations when contrasted and that of the 2DOF-FOPIDN regulator. The above examination uncovered that the cascade 2-DOF-PIDN-FOPIDN regulator has less pinnacle variation, the degree of oscillations, and quicker settling time than the 2DOF-FOPIDN regulator in all the contextual analyses and demonstrates predominant execution for controlling system oscillations.

The result of HES and IPFC units are consolidated in the AGC circle for the test framework. The unique reactions have been analyzed utilizing the best-acquired regulator course 2-DOF-PIDN-FOPIDN in the presence and nonappearance of HES and IPFC in Figure 8. The setting time and pinnacle over and undershoot of region frequency variations and tie-line power variation of the test framework without/with HES and IPFC under various un-contracted burden request change conditions and are shown up in Tables 1 and 2 separately. From Figure 8 and Tables 1 and 2, it very well may be seen that the frequency variations of both region and tie-line power variations have been worked on as much as the small peak deviations and settling time for the two-area multi-source thermal-hydro-wind rebuilt power framework with HES and IPFC unit under different un-contracted step load demand change conditions. 




Figure.8 (a) Dynamic responses of the frequency deviations of Area-1

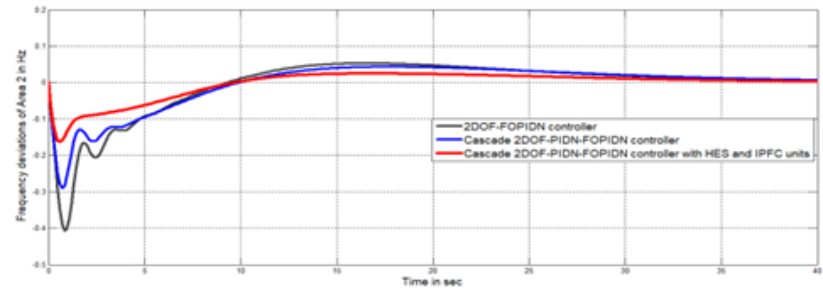

Figure.8 (b) Dynamic responses of the frequency deviations of Area-2

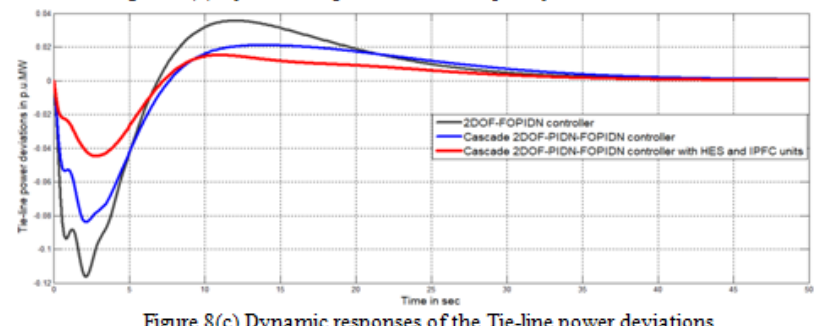

Figure.8(c) Dynamic responses of the Tie-line power deviations

Fig 8. Dynamic responses of the change in frequency and tie-line power deviations for the test system using proposed controllers without and with HES and IPFC units under Poolco based transactions (Case-1)

\subsection{Scenario 2: Bilateral based transaction}

In these trades, all the Discos have a concurrence with the Gencos and the accompanying with DPM implying Eqn. (35) is considered as

$$
D P M_{2}=\left[\begin{array}{llll}
0.4 & 0.5 & 0.2 & 0.2 \\
0.3 & 0.3 & 0.1 & 0.1 \\
0.2 & 0.1 & 0.5 & 0.4 \\
0.1 & 0.1 & 0.2 & 0.3
\end{array}\right]
$$

For the present circumstance, each Disco requests 0.25, p.u.MW for each from Gencos as portrayed by cpf in the DPM matrix. The proposed regulators are executed in a suggested test system under various un-contracted step load demand change conditions and compared with the 2DOF-FOPIDN controller. The comparative transient performances of test systems with various sorts of controllers have shown up in Fig. 9. A similar investigation of dynamic exhibitions of the setting time and pinnacle over/undershoot based region frequencies and tie-line power varieties of the test frameworks utilizing 2DOF-FOPIDN and course 2DOF-PIDN-FOPIDN regulators for various contextual analyses has shown up in Table 3 and 4, separately. From Tables 3 and 4 and Fig 9, it is apparent that the proposed course 2DOF-PIDN-FOPIDN regulator is superior to the 2DOFFOPIDN regulator due to more modest pinnacle varieties, settling time, and diminished oscillations.

The unique reactions of region frequency deviations and tie-line power variation of the test framework without/with HES and IPFC units utilizing the best-got course 2DOF-PIDN-FOPIDN regulator are displayed in Figure 9 in case-1. The nearunique exhibitions of setting time and pinnacle over/undershoot based region frequencies and tie-line power variations of test framework without and with HES and IPFC units utilizing course 2DOF-PIDN-FOPIDN regulators under various uncontracted step load demand change conditions have shown up in Tables 3 and 4 autonomously. From Tables 3 and 4 and Figure 9, it very well may be seen that the frequency variations of both region and tie-line power variations have been worked on as far as lesser settling time and undershoot of the test framework with HES and IPFC under various un-contracted step load demand change conditions. 


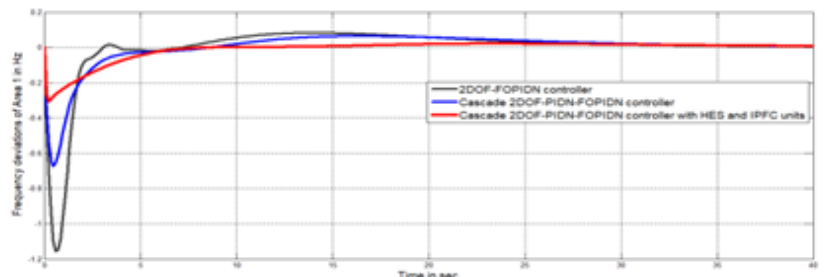

Figure.9 (a) Dynamic responses of the frequency deviations of Area-1

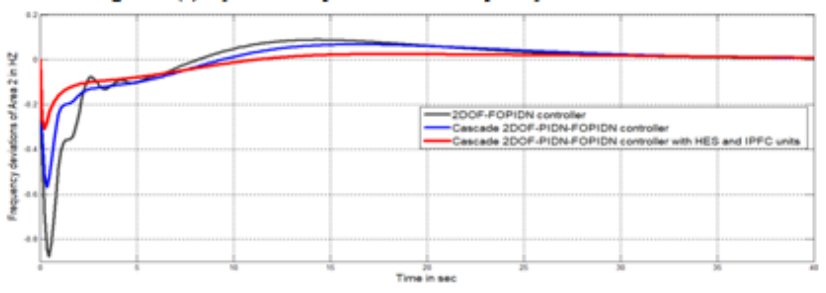

Figure.9 (b) Dynamic responses of the frequency deviations of Area-2

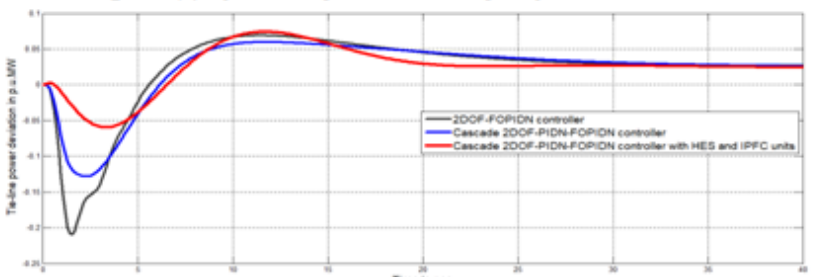

Figure.9(c) Dynamic responses of the Tie-line power deviations (actual)



Figure.9 (d) Dynamic responses of the Tie-line power deviations (error)

Fig 9. Dynamic responses of the change in frequency deviations and tie-line power deviations for the test system using proposed controllers without and with HES and IPFC units under Bilateral based transactions (Case-1)

Table 1. Settling time-based area frequencies and tie-line power deviations of test system using proposed controllers without and with HES and IPFC units under Poolco based transactions

\begin{tabular}{|c|c|c|c|c|c|c|c|c|c|}
\hline \multirow[t]{2}{*}{$\begin{array}{l}\text { Test } \\
\text { system }\end{array}$} & \multicolumn{3}{|c|}{$\begin{array}{l}\text { Settling time using 2DOF-FOPIDN } \\
\text { controllers }\end{array}$} & \multicolumn{3}{|c|}{$\begin{array}{l}\text { Settling time using cascade 2-DOF- } \\
\text { PIDN-FOPIDN controllers }\end{array}$} & \multicolumn{3}{|c|}{$\begin{array}{l}\text { Settling time using cascade2-DOF } \\
\text { PIDN-FOPIDN controllers with } \\
\text { HES and IPFC }\end{array}$} \\
\hline & $\begin{array}{l}\mathrm{DF}_{1} \text { in } \\
\text { sec }\end{array}$ & $\begin{array}{l}\mathrm{DF}_{2} \text { in } \\
\text { sec }\end{array}$ & $\begin{array}{l}\mathrm{DP}_{t i e} \text { in } \\
\text { sec }\end{array}$ & $\begin{array}{l}\mathrm{DF}_{1} \text { in } \\
\text { sec }\end{array}$ & $\begin{array}{l}\mathrm{DF}_{2} \text { in } \\
\text { sec }\end{array}$ & $\begin{array}{l}\mathrm{DP}_{t i e} \text { in } \\
\text { sec }\end{array}$ & $\begin{array}{l}\mathrm{DF}_{1} \text { in } \\
\text { sec }\end{array}$ & $\begin{array}{l}\mathrm{DF}_{2} \text { in } \\
\text { sec }\end{array}$ & $\begin{array}{l}\mathrm{DP}_{t i e} \text { in } \\
\text { sec }\end{array}$ \\
\hline Case 1 & 28.396 & 26.549 & 25.141 & 24.939 & 23.306 & 21.663 & 20.156 & 19.523 & 17.88 \\
\hline Case 2 & 30.973 & 27.973 & 25.97 & 27.516 & 24.73 & 22.492 & 22.733 & 20.947 & 18.709 \\
\hline Case 3 & 31.659 & 29.429 & 26.562 & 28.202 & 26.186 & 23.084 & 23.419 & 22.403 & 19.301 \\
\hline Case 4 & 33.966 & 31.531 & 27.973 & 30.509 & 28.288 & 24.495 & 25.726 & 24.505 & 20.712 \\
\hline Case 5 & 35.532 & 32.862 & 29.966 & 32.075 & 29.619 & 26.488 & 27.292 & 25.836 & 22.705 \\
\hline Case 6 & 37.129 & 35.822 & 32.031 & 33.672 & 32.579 & 28.553 & 28.889 & 28.796 & 24.77 \\
\hline Case 7 & 38.662 & 37.98 & 33.553 & 35.205 & 34.737 & 30.075 & 30.422 & 30.954 & 26.292 \\
\hline Case 8 & 41.579 & 39.339 & 35.432 & 38.122 & 36.096 & 31.954 & 33.339 & 32.313 & 28.171 \\
\hline Case 9 & 42.532 & 41.663 & 35.552 & 39.075 & 38.42 & 32.074 & 34.292 & 34.637 & 28.291 \\
\hline $\begin{array}{l}\text { Case } \\
10\end{array}$ & 43.662 & 42.551 & 37.965 & 40.205 & 39.308 & 34.487 & 35.422 & 35.525 & 30.704 \\
\hline
\end{tabular}


Table 2. Peak over/undershoot-based area frequencies and tie-line power deviations of test system using proposed controllers without and with HES and IPFC units under Poolco based transactions

\begin{tabular}{|c|c|c|c|c|c|c|c|c|c|}
\hline \multirow[t]{2}{*}{$\begin{array}{l}\text { Test } \\
\text { system }\end{array}$} & \multicolumn{3}{|c|}{$\begin{array}{l}\text { Peak over/under shoot using 2DOF- } \\
\text { FOPIDN controllers }\end{array}$} & \multicolumn{3}{|c|}{$\begin{array}{l}\text { Peak over/under shoot using } \\
\text { cascade2-DOF-PIDN-FOPIDN } \\
\text { controllers }\end{array}$} & \multicolumn{3}{|c|}{$\begin{array}{l}\text { Peak over/under shoot using cas- } \\
\text { cade 2-DOF-PIDN-FOPIDN con- } \\
\text { trollers with HES and IPFC }\end{array}$} \\
\hline & $\mathrm{Hz}^{\mathrm{DF}_{1} \text { in }}$ & $\mathrm{Hz}^{\mathrm{DF}_{2} \text { in }}$ & $\begin{array}{l}\text { DP }_{t i e} \text { in } \\
\text { p.u.MW }\end{array}$ & $\mathrm{Hz}^{\mathrm{DF}_{1} \text { in }}$ & $\mathrm{Hz}_{2} \mathrm{DF}_{2}$ in & $\begin{array}{l}\text { DP }_{t i e} \text { in } \\
\text { p.u. MW }\end{array}$ & $\mathrm{Hz}^{\mathrm{DF}_{1} \text { in }}$ & $\mathrm{Hz}^{\mathrm{DF}_{2} \text { in }}$ & $\begin{array}{l}\mathrm{DP}_{t i e} \text { in } \\
\text { p.u.MW }\end{array}$ \\
\hline Case 1 & 0.5581 & 0.4025 & 0.1166 & 0.3929 & 0.2769 & 0.0834 & 0.2183 & 0.1631 & 0.0446 \\
\hline Case 2 & 0.5702 & 0.4495 & 0.1473 & 0.405 & 0.3239 & 0.1141 & 0.2304 & 0.2101 & 0.0753 \\
\hline Case 3 & 0.5747 & 0.4688 & 0.156 & 0.4095 & 0.3432 & 0.1228 & 0.2349 & 0.2294 & 0.084 \\
\hline Case 4 & 0.5874 & 0.4827 & 0.1743 & 0.4222 & 0.3571 & 0.1411 & 0.2476 & 0.2433 & 0.1023 \\
\hline Case 5 & 0.6063 & 0.5166 & 0.1967 & 0.4411 & 0.391 & 0.1635 & 0.2665 & 0.2772 & 0.1247 \\
\hline Case 6 & 0.6143 & 0.5498 & 0.2099 & 0.4491 & 0.4242 & 0.1767 & 0.2745 & 0.3104 & 0.1379 \\
\hline Case 7 & 0.6401 & 0.5665 & 0.2304 & 0.4749 & 0.4409 & 0.1972 & 0.3003 & 0.3271 & 0.1584 \\
\hline Case 8 & 0.7058 & 0.5907 & 0.2366 & 0.5406 & 0.4651 & 0.2034 & 0.366 & 0.3513 & 0.1646 \\
\hline Case 9 & 0.7265 & 0.6534 & 0.2471 & 0.5613 & 0.5278 & 0.2139 & 0.3867 & 0.414 & 0.1751 \\
\hline Case 10 & 0.7396 & 0.6776 & 0.2617 & 0.5744 & 0.552 & 0.2285 & 0.3998 & 0.4382 & 0.1897 \\
\hline
\end{tabular}

Table 3. Settling time-based area frequencies and tie-line power deviations of test system using proposed controllers without and with HES and IPFC under Bilateral based transactions

\begin{tabular}{|c|c|c|c|c|c|c|c|c|c|}
\hline \multirow[t]{2}{*}{$\begin{array}{l}\text { Test } \\
\text { system }\end{array}$} & \multicolumn{3}{|c|}{$\begin{array}{l}\text { Settling time of test system using } \\
\text { 2DOF-FOPIDN controllers }\end{array}$} & \multicolumn{3}{|c|}{$\begin{array}{l}\text { Settling time of test system using } \\
\text { cascade 2-DOF-PIDN-FOPIDN con- } \\
\text { trollers }\end{array}$} & \multicolumn{3}{|c|}{$\begin{array}{l}\text { Settling time of test system using } \\
\text { cascade 2-DOF-PIDN-FOPIDN con- } \\
\text { trollers with HES and IPFC }\end{array}$} \\
\hline & $\begin{array}{ll}\mathrm{DF}_{1} & \text { in } \\
\mathrm{sec} & \end{array}$ & $\begin{array}{l}\mathrm{DF}_{2} \text { in } \\
\sec \end{array}$ & $\underset{\text { sec }}{\mathbf{D P}_{\text {tie }}}$ in & $\begin{array}{l}\mathrm{DF}_{1} \text { in } \\
\sec \end{array}$ & $\begin{array}{l}\mathrm{DF}_{2} \text { in } \\
\text { sec }\end{array}$ & $\begin{array}{l}\mathrm{DP}_{\text {tie }} \text { in } \\
\text { sec }\end{array}$ & $\begin{array}{ll}\mathrm{DF}_{1} \text { in } \\
\text { sec }\end{array}$ & $\begin{array}{l}\mathrm{DF}_{2} \text { in } \\
\text { sec }\end{array}$ & $\begin{array}{l}\mathrm{DP}_{\text {tie }} \text { in } \\
\mathrm{sec}\end{array}$ \\
\hline Case 1 & 23.332 & 21.485 & 22.046 & 18.543 & 16.722 & 18.568 & 14.761 & 12.939 & 14.785 \\
\hline Case 2 & 25.994 & 22.999 & 22.963 & 21.205 & 18.236 & 19.485 & 17.422 & 14.453 & 15.702 \\
\hline Case 3 & 26.685 & 24.455 & 23.557 & 21.896 & 19.692 & 20.079 & 18.113 & 15.909 & 16.296 \\
\hline Case 4 & 28.992 & 26.557 & 24.971 & 24.203 & 21.794 & 21.493 & 20.423 & 18.011 & 17.713 \\
\hline Case 5 & 30.562 & 27.891 & 26.961 & 25.771 & 23.128 & 23.483 & 21.988 & 19.345 & 19.702 \\
\hline Case 6 & 32.155 & 30.855 & 29.026 & 27.366 & 26.092 & 25.548 & 23.583 & 22.309 & 21.765 \\
\hline Case 7 & 33.689 & 33.004 & 30.552 & 28.902 & 28.241 & 27.072 & 25.117 & 24.458 & 23.289 \\
\hline Case 8 & 36.605 & 34.365 & 31.427 & 31.816 & 29.602 & 27.949 & 28.033 & 25.819 & 24.166 \\
\hline Case 9 & 37.561 & 36.689 & 32.547 & 32.771 & 31.926 & 29.069 & 28.988 & 28.143 & 25.286 \\
\hline Case 10 & 38.691 & 37.574 & 34.961 & 33.902 & 32.811 & 31.482 & 30.119 & 29.028 & 27.699 \\
\hline
\end{tabular}

\section{Conclusions}

The cascade 2-DOF-PIDN-FOPIDN controllers are arranged and executed in a two-area multi-source thermal-hydro-wind rebuilt power structure without and with HES and IPFC units for different sorts' trades under different un-contracted step load demand change conditions. The BUZOA technique has been utilized to decide the optimal parameters of the cascade 2-DOF-PIDN-FOPIDN regulator. Assessment reveals on connection of dynamic responses the proposed cascade 2-DOFPIDN-FOPIDN controller in all exchange arrangements investigates the pervasiveness to the extent less pinnacle deviations and settling time of the test frameworks contrasted with the 2DOF-FOPIDN regulator. The huge benefit of cascade 2-DOFPIDN-FOPIDN regulators is adaptability in controlling reason, which assists with giving remedial measures to be taken up for the AGC issues and amazing ability of taking care of parameter vulnerability, elimination of steady-state error, and guarantees better stability. It is also inferred that the use of HES and IPFC units have been improved the system dynamic performance of area frequencies and tie-line power oscillations under different un-contracted step load demand change conditions in terms of reduced peak deviations, settling time and magnitude of oscillations. 
Table 4. eak over/undershoot-based area frequencies and tie-line power deviations of test system using proposed controllers without and with HES and IPFC units under Bilateral based transactions

\begin{tabular}{|c|c|c|c|c|c|c|c|c|c|}
\hline \multirow[t]{2}{*}{$\begin{array}{l}\text { Test } \\
\text { system }\end{array}$} & \multicolumn{3}{|c|}{$\begin{array}{l}\text { Peak over/under shoot using 2DOF- } \\
\text { FOPIDN controllers }\end{array}$} & \multicolumn{3}{|c|}{$\begin{array}{l}\text { Peak over/under shoot using cascade } \\
\text { 2-DOF-PIDN-FOPIDN controllers }\end{array}$} & \multicolumn{3}{|c|}{$\begin{array}{l}\text { Peak over/under shoot using cas- } \\
\text { cade 2-DOF-PIDN-FOPIDN con- } \\
\text { trollers with HES and IPFC }\end{array}$} \\
\hline & $\mathrm{DF}_{1}$ in $\mathrm{Hz}$ & $\mathrm{DF}_{2}$ in $\mathrm{Hz}$ & $\begin{array}{l}\text { DP }_{t i e} \text { in } \\
\text { p.u. } \mathrm{MW}\end{array}$ & $\mathrm{DF}_{1}$ in $\mathrm{Hz}$ & $\mathrm{DF}_{2}$ in $\mathrm{Hz}$ & $\begin{array}{l}\mathrm{DP}_{t i e} \text { in } \\
\text { p.u. } \mathrm{MW}\end{array}$ & $\mathrm{DF}_{1}$ in $\mathrm{Hz}$ & $\mathrm{DF}_{2}$ in $\mathrm{Hz}$ & $\begin{array}{l}\text { DP }_{t i e} \text { in } \\
\text { p.u. } \mathrm{MW}\end{array}$ \\
\hline Case 1 & 1.1672 & 0.8627 & 0.2179 & 0.6507 & 0.5671 & 0.1277 & 0.0304 & 0.3072 & 0.0592 \\
\hline Case 2 & 1.1792 & 0.9097 & 0.2487 & 0.6627 & 0.6142 & 0.1585 & 0.0424 & 0.3542 & 0.0898 \\
\hline Case 3 & 1.1837 & 0.9291 & 0.2574 & 0.6672 & 0.6333 & 0.1672 & 0.0469 & 0.3735 & 0.0985 \\
\hline Case 4 & 1.1964 & 0.9429 & 0.2757 & 0.6799 & 0.6472 & 0.1855 & 0.0596 & 0.3874 & 0.1168 \\
\hline Case 5 & 1.2153 & 0.9768 & 0.2981 & 0.6988 & 0.6811 & 0.2079 & 0.0785 & 0.4213 & 0.1392 \\
\hline Case 6 & 1.2233 & 1.0101 & 0.3113 & 0.7068 & 0.7143 & 0.2211 & 0.0865 & 0.4545 & 0.1524 \\
\hline Case 7 & 1.2492 & 1.0267 & 0.3318 & 0.7327 & 0.7311 & 0.2416 & 0.1124 & 0.4712 & 0.1729 \\
\hline Case 8 & 1.3148 & 1.0509 & 0.3379 & 0.7983 & 0.7552 & 0.2477 & 0.178 & 0.4954 & 0.1792 \\
\hline Case 9 & 1.3355 & 1.1136 & 0.3485 & 0.819 & 0.8179 & 0.2583 & 0.1987 & 0.5581 & 0.1896 \\
\hline Case 10 & 1.3486 & 1.1378 & 0.3631 & 0.8321 & 0.8421 & 0.2729 & 0.2118 & 0.5823 & 0.2042 \\
\hline
\end{tabular}

\section{References}

1) Kamarudin MN, Shaharudin N, Rahman NHA, Hairi MH, Rozali SM, Sutikno T. Review on load frequency control for power system stability. TELKOMNIKA (Telecommunication Computing Electronics and Control). 2021;19(2):638-638. Available from: https://dx.doi.org/10.12928/telkomnika. v19i2.16118. doi:10.12928/telkomnika.v19i2.16118.

2) Mohamed TH, Alamin MAM, Hassan AM. A novel adaptive load frequency control in single and interconnected power systems. Ain Shams Engineering Journal. 2021;12(2):1763-1773. Available from: https://dx.doi.org/10.1016/j.asej.2020.08.024. doi:10.1016/j.asej.2020.08.024.

3) Kumar R, Sharma VK. Whale Optimization Controller for Load Frequency Control of a Two-Area Multi-source Deregulated Power System. International Journal of Fuzzy Systems. 2020;22(1):122-137.

4) Pappachen A, Fathima AP. Critical research areas on load frequency control issues in a deregulated power system: A state-of-the-art-of-review. Renewable and Sustainable Energy Reviews. 2017;72:163-177. Available from: https://dx.doi.org/10.1016/j.rser.2017.01.053. doi:10.1016/j.rser.2017.01.053.

5) Latif A, Hussain SMS, Das DC, Ustun TS. State-of-the-art of controllers and soft computing techniques for regulated load frequency management of single/multi-area traditional and renewable energy based power systems. Applied Energy. 2020;266:114858-114858. Available from: https://dx.doi.org/ 10.1016/j.apenergy.2020.114858. doi:10.1016/j.apenergy.2020.114858.

6) Sahu RK, Panda S, Biswal A, Sekhar GTC. Design and analysis of tilt integral derivative controller with filter for load frequency control of multi-area interconnected power systems. ISA Transactions. 2016;61:251-264. Available from: https://dx.doi.org/10.1016/j.isatra.2015.12.001. doi:10.1016/j.isatra.2015.12.001.

7) Al-Mayyahi A, Aldair AA, Chatwin C. Control of a 3-RRR Planar Parallel Robot Using Fractional Order PID Controller. International Journal of Automation and Computing. 2020;17(6):822-836. Available from: https://dx.doi.org/10.1007/s11633-020-1249-9. doi:10.1007/s11633-020-1249-9.

8) Mohapatra TK, Dey AK, Sahu BK. Employment of quasi oppositional SSA-based two-degree-of-freedom fractional order PID controller for AGC of assorted source of generations. IET Generation, Transmission \& Distribution. 2020;14(17):3365-3376. Available from: https://dx.doi.org/10.1049/iet-gtd. 2019.0284. doi:10.1049/iet-gtd.2019.0284.

9) Simhadri K, Acharyulu BV, Mohanty B, Goutham KS. WOA Optimized 2DOF TIDF Controller for Automatic Generation Control of Hydro-Thermal System. InIntelligent Computing in Control and Communication. Singapore. Springer. 2021.

10) Arshaghi A, Ashourian M, Ghabeli L. Buzzard optimization algorithm: A nature-inspired metaheuristic algorithm. Majlesi Journal of Electrical Engineering. 2019;13(3):83-98.

11) Chandrasekar K, Paramasivam B, Chidambaram IA. Ancillary Service Requirement Assessment Indices Evaluation with Proportional and Integral plus Controller in a Restructured Power System with Hydrogen Energy Storage Unit. Middle-East Journal of Scientific Research. 2016;24(12):3838-3857.

12) BASKAR B, PARAMASIVAM B. FRACTIONAL ORDER PID CONTROLLER FOR AGC LOOP OF A TWO-AREA SOLAR-THERMAL DEREGULATED POWER SYSTEM WITH RFB AND IPFC UNIT. INTERNATIONAL JOURNAL OF ELECTRICAL ENGINEERING \& TECHNOLOGY. 2019;10(2):24-35. Available from: https://dx.doi.org/10.34218/ijeet.10.2.2019.003. doi:10.34218/ijeet.10.2.2019.003. 